\author{
Abisheva Onal Tokkulovna, professor \\ Institute of Arts, culture and sport \\ Abai Kazakh National Pedagogical University \\ Almaty, the Republic of Kazakhstan \\ E-mail: artbura@gmail.com \\ ORCID ID 0000-0003-0283-8758
}

\title{
SMART-TECHNOLOGIES IN HIGH SCHOOL
}

Annotation: In this article, the author discusses the problems of using Smart information technologies in the educational process. In current conditions there is a necessity of smart education as a natural trend in contemporary global education: flexibility of education in interactive educational environments; personalization and adaptation of learning; free access to content worldwide. Smart learning is achieved through the use of technological innovation and the Internet, which provides students with the opportunity to acquire professional competences on the basis of a systematic and multidimensional vision of the study subjects with regard to their complexity and continuous content updates. Smart environment for students: smart, interdisciplinary-oriented educational system of lifelong education (school, University, corporate training): - adaptive educational programme, portfolio; more information about students; technology of collaborative learning - creation of knowledge.

Keywords: Smart-technologies, information technologies, Internet, continuous education, technological innovations, portfolio.

Абишева Онал Токкуловна, профессор доктор искусствоведения кафедры творческих специальности Казахский национальный педагогический университет им. Абая

Алматы, Казахстан

E-mail: artbura@gmail.com ORCIDID0000-0003-0283-8758

\section{SMART-TЕХНОЛОГИИ В ВЫСШЕЙ ШКОЛЕ}

\begin{abstract}
Аннотация: $B$ данной статье рассмотрень проблемьл использования Смарт информационных технологий в учебном процессе. $B$ современных условиях возникает необходимость smart-образования как закономерного направления в современном глобальном образовании: гибкость обучения в интерактивной образовательной среде; персонализацию и адаптачию обучения; свободный доступ к контенту по всему миру. СМАРТ обучение реализуется с использованием технологических инноваций и Интернета, который предоставляет студентам возможность приобретения профессиональных компетенций на основе системного многомерного видения и изучения дисциплин с учетом их многоаспектности и непрерывного обновления содержания. Смарт среда для обучающихся: умные, междисциплинарные, ориентированные на них образовательные системы непрерывного образования (икола, высшее учебное заведение, корпоративное обучение): - адаптивные образовательные программы, портфолио; больше информации об обучающихся;- технологии совместного обучения - создания знаний;
\end{abstract}

Ключевые слова: Смарт-технологий, информационные технологий, интернет, непрерывное образование, технологические инновачии, портфолио.

Основная идея современного образования заключается в признании новых источников познания, которые выступают как закономерные, наряду с традиционными: лекция, семинар, практические занятие и др.

Smart - технологии в высшей школе
Материалы Международной практической интернет-конференции «Актуальные Проблемы Науки» 
Видоизменяется роль преподавателя, который, в случае использования smartтехнологий, должен создавать новую систему контроля. В глобальном мире возникает необходимость научного отбора «нужных» знаний уже на качественном, современном уровне.

Smart-образование - это по своему статусу: само планируемое самообразование для жизни, самореализации человека, успешной личной карьеры, а также для получения профессии в интересах общества и производства.

XXI век - это век, когда информационные технологии становятся неотъемлемой частью современного общества. Сегодня с уверенностью можно констатировать факт существования нового цифрового (сетевого) поколения людей, для которых мобильный телефон, компьютер и Интернет являются такими же естественными элементами их жизненного пространства, как природа и общество.

Содержание и образовательные технологии smart-образования направлены на опережающее образование, в котором уровень профессионализма выпускников, уровень развития их личности должен опережать и формировать уровень развития производства, его технологий, определять в партнерстве вуз-предприятие структуру рынка труда. В настоящее время уже становится нормой проведение учебных занятий со студентами с использованием мультимедийных презентаций, сделанных в таких программных пакетах, как Microsoft Power Point или Macromedia Flash. Однако, наряду с привычными презентационными технологиями в сферу образования проникают новые, так называемые, интерактивные технологии.

Smart-образование это образование креативное, всеобщее, в течение всей жизни, бессрочное, не ограниченное рамками социальных институтов, естественно вписанное в жизненный уклад человека; Во время работы на интерактивных досках у обучающихся улучшается концентрация внимания, быстрее усваивается учебный материал, и в результате повышается успеваемость каждого из учащихся. Внедрение новых технологий в сферу образования ведет за собой переход от старой схемы репродуктивной передачи знаний к новой, креативной форме обучения.

Одна из главных задач современного образования - это создание устойчивой мотивации учащихся к получению знаний, другая - поиск новых форми инструментов освоения этих знаний с помощью творческий решений. СМАРТ общество ставит перед университетами новую глобальную задачу: подготовку кадров, обладающих креативным потенциалом, умеющих думать и работать в новом мире.

Задачи педагогов в системе Smart-образования: создание студентам по формированию развивающейся персональной образовательной среды для успешного усвоения новых, прогрессивных знаний, развития и совершенствования компетенций, самостоятельного обучения.

Обеспечение сотрудничества с студентами, студентами между собой, социальными сетями, с профессиональными сообществами для достижения оптимального уровня дифференциализации индивидуализации учебного процесса;

Создание образовательной деятельности с элементами сотрудничества для студентов.

Образование смещается в сторону самоконтроля и самооценки студентов, а также оценки преподавателя.

Образование должно стать публично обсуждаемым и открытым для критики. В системе smart-образования акцентировать на следующие индивидуальные особенности студента:

Smart - технологии в высшей школе
Материалы Международной практической интернет-конференции «Актуальные Проблемы Науки» 
Текущее(актуальное)функциональное состояние студента. Сформировавшийся стиль познавательной деятельности (дедуктивный, индуктивный, продуктивный, диалектический).

Мотивы познавательной коммуникативная).Познавательные

\section{деятельности} возможности (академическая, (высокие, деловая, хорошие, личностных особенностей студентов.

В современных условиях возникает необходимость smart-образования как закономерного направления в современном глобальном образовании.

Основная идея этого образования заключается в признании новых источников познания, которые выступают как закономерные, наряду с традиционными: лекция, семинар, практические занятие и др.

Видоизменяется роль преподавателя, который, в случае использования smartтехнологий, должен создавать новую систему контроля. В глобальном мире возникает необходимость научного отбора «нужных» знаний уже на качественном, современном уровне.

В учебном процессе используются различные медиа компоненты: электронные учебники, презентации лекций, компьютерный практикум и тестирование, различные инновационные технологии. Все это дает новую возможность активнее использовать информационные ресурсы и телекоммуникации, создавать новые инновационные методы и методики в образовании.

В результате использования smart-образования:

Увеличится объем знаний;

Студенты смогут мобильнее получать необходимую информацию по дисциплинам;

При внедрении smart-технологии в образовательный процесс, резко повыситься уровень использования инновационных технологии;

Мобильное установления сотрудничества не только в рамках университета, но и создание сети обмена информацией между несколькими региональными и международными университетами.

Уникальные возможности smart-образования, являются перспективными и необходимыми в современном образовательном процессе.

Smart - технологии в образовании уже является стандартом во многих странах. Сегодня знания передаются не только от преподавателя к студенту, но и между студентами, что позволяет создавать новый уровень знаний. В свою очередь активно начинают применяться образовательные технологии и преподаватели могут нести знания не только в аудитории.

Smart - технологии в образовании - это объединение учебных заведений и профессорско-преподавательского состава для осуществления совместной образовательной деятельности в сети Интернет на базе общих стандартов, соглашений и технологий. То есть речь идет о совместном создании и использовании контента, о совместном обучении. Примером тому может служить проект следующего десятилетия в европейской системе образования - Единый европейский университет с общим деканатом, который будет сопровождать перемещение студентов от вуза к вузу.

Можно также сказать, что Smart- технологии в образовании, - это гибкое обучение в интерактивной образовательной среде с помощью контента со всего мира, находящегося в свободном доступе. Ключ к пониманию Smarteducation - широкая доступность знаний. СМАРТ образования в университете научно-педагогическим работникам важно строго соблюдать существующие интеллектуальные технологии его внедрения, которые должны

Smart - технологии в высшей школе
Материалы Международной практической интернет-конференции «Актуальные Проблемы Науки» 
осуществляться с учетом личных требований и предпочтений обучающегося. Для этого необходимо: использовать индивидуальный график обучения, поддерживать постоянный контакт студента с преподавателем, добиваться прочного усвоения знаний, использовать удобное время и место обучения.

В настоящее время происходит переход от e-learning к Smart (англ. - умный, сообразительный, энергичный) e-learning и Smart Education (умное образование). Концепция Smart-образования - гибкость, предполагающая наличие большого количества источников, максимальное разнообразие мультимедиа, способность быстро и просто настраивается под уровень и потребности слушателя.

Для развития образования уже недостаточно влияния человеческого капитала. Необходимо изменять саму образовательную среду, не просто наращивать объёмы образования трудовых ресурсов, должно качественно измениться само содержание образования, его методы, инструменты и среды, необходим переход к SMARTобразованию.

В свою очередь цель умного обучения заключается в том, чтобы сделать процесс обучения наиболее эффективным за счет переноса образовательного процесса в электронную среду. Именно такой подход позволит скопировать знания преподавателя и предоставить доступ к ним каждому желающему. Более того, это позволит расширить границы обучения, причем не только с точки зрения количества обучаемых, но и с точки зрения временных и пространственных показателей: Обучение станет доступным везде и всегда. Одним из условий перехода к умному электронному обучению является переход от книжного контента к активному. Лишь знания в электронном виде можно передавать с наибольшей эффективностью. При этом знания должны располагаться в едином контексте, предполагающем наличие интеллектуальной системы поиска.

\section{Литературы}

1. Тихомирова Н. В., Минашкин В. Г., Дубейковская Л. Н. Образовательный процесс в электронном университете: условия и направления трансформации // Информационное общество. 2011. №3. С. 35-44.

2. Лапчик М. П. Дистанционные технологии в системе инновационного педагогического образования // Инновации в непрерывном образовании. 2011. №2. С. 5-10.

3. Тихомиров В. П. Мир на пути к SmartEducation. Новые возможности для развития // Открытое образование. 2011. №3. С. 22-28.

4. Coombs Ph. H., Manzoor A. Attacking Rural Poverty: How Non-Formal Education can Help. Baltimore. Johns Hopkins University Press, 1974.

5. Гуманитарные аспекты образования, творчества и свободы личности: Сборник статей / М.Е. Кудрявцева. - М.: Директ-Медиа, 2014.

6. Гоник И.Л. Инновационная модернизация России и новая миссия российских университетов в условия глобализации образовательного пространства: монография. Минобрнауки РФ, Волгоградскийгос. технический ун-т. Волгоград: ВолгГТУ, 2013.

7. Завражин А. В. СМАРТ как ключевое направления научно-технического процесса/СМАРТ: содержание и особенности проникновения в современное общество. Монография. М.: МЭСИ, 2015.

8. Тихомиров В. П. Мир на пути Smarteducation. Новые возможности для развития // Открытое образование. Научно-практический журнал. Специальный выпуск: Смарттехнологии в образований, 2017.

9. Прикладная информатика/Journal of Appied informatics [Tom 13, №2(74). 2018]

10. Абишева О. Т. Жақандану үрдістерінің аймақтағы көркем өнер білім берудің әскрі.Серия Художественное образование. №2 (55), 2018, С.6-7.

Smart - технологии в высшей школе
Материалы Международной практической интернет-конференции «Актуальные Проблемы Науки» 